Research Article

\title{
Research on the Infrared Thermographic Detection of Concrete under Solar Heating
}

\author{
Dan Zheng $\mathbb{D}$, ${ }^{1}$ Shuaishuai Tan $\mathbb{D}^{1},{ }^{1}$ Xinxin $L i \mathbb{D},{ }^{1,2}$ and Haonan Cai $\mathbb{D}^{1}$ \\ ${ }^{1}$ College of River and Ocean Engineering, Chongqing Jiaotong University, Chongqing 400074, China \\ ${ }^{2}$ College of Water Conservancy and Environmental Engineering, Zhengzhou University, Zhengzhou 450001, China
}

Correspondence should be addressed to Xinxin Li; 990201600023@cqjtu.edu.cn

Received 10 December 2020; Revised 14 January 2021; Accepted 21 January 2021; Published 4 February 2021

Academic Editor: Xianming Shi

Copyright (c) 2021 Dan Zheng et al. This is an open access article distributed under the Creative Commons Attribution License, which permits unrestricted use, distribution, and reproduction in any medium, provided the original work is properly cited.

Infrared thermography for detecting defects in concrete structures is closely related to the heat source and the optimized method of the thermal image. Due to the limitation of the irradiation area of the heat source, it is inefficient to detect the defects in large concrete structures. In this paper, sunlight was employed as a heat source to detect the defects with different sizes and depths in concrete, and the measured infrared images were processed and optimized by an enhancement algorithm. The experimental results showed that the defects in concrete could be rapidly identified under sunlight. The effect of environment, view angle, and boundary can be eliminated by image preprocessing, and the histogram equalization algorithm can increase the detection depth of the defects. The research results can also provide a reference for the infrared detection technology of concrete under the weak heat source.

\section{Introduction}

Nondestructive testing (NDT) of concrete is critical to evaluate the safety of structures, and infrared thermography (IRT) is one of the most important internal defect detection methods available. When the heating source is applied on the concrete, due to the poor thermal conductivity of the gas contained in the internal defects, energy could not pass through and accumulate on the top region of the defect, causing the surface temperature above the defect higher than the intact area. Therefore, infrared thermography can be used to collect the surface temperature information and detect the internal defects in concrete $[1,2]$. The variation of temperature in different parts of the concrete depends on the depth and size of the defects. However, this method is not effective for detecting deep defects [3-5]. Maierhofer studied the influence of the size and depth of the cavity on the transient temperature curve under different heating times, realizing the locating of the internal defects in concrete [6]. Patricia further observed that the maximum detection depth is related to the horizontal dimensions of the defects [7].
Although the thermal conductivity of concrete is two orders of magnitude higher than that of gas, its value is still low, and identification of defects may take a long time. Thus, researchers began to focus on improving the heating mode and optimizing the thermal image. The test results show that a clear thermal image can be obtained by heating the specimen with a strong heat source $[8,9]$. Krishnendu compared the infrared inspection results of concrete under various heating methods and found that the high-resolution infrared images can be obtained by frequency modulation heating mode [10].

For large concrete structures, the defects are randomly distributed in the structure. Owing to the limitation of the heat source, it is inefficient to divide the structure into small parts for detection. As a natural heat source, sunlight can be evenly applied to the structure, and the heating range could be effectively expanded [11]. However, the radiant intensity of sunlight applied to the structure is small, and a stable environment is needed to reduce the influence of external factors (e.g., wind, moisture evaporation, and boundary) on the surface temperature of the inspected object [12]. 
Therefore, it is necessary to optimize the measured results under solar heating.

Digital image processing is an applied science, which can realize image nonuniformity correction and contrast enhancement [13]. Existing studies have shown that the processing method based on color histogram is widely applied to infrared image optimization, which can achieve the purpose of expanding the gray range and improving contrast, and the types of derived algorithms are gradually enriched, such as the global histogram equalization (GHE) and the contrast limit adaptive histogram equalization (CLAHE) [14, 15]. Scholars have used this enhancement method to reduce the limit of contrast in infrared images for visual observation and improve the recognition effect [16].

This paper aims to present an experimental investigation into the surface temperature distribution of concrete under solar heating. The effect of the depth and size of the defects, the heat source, the boundary condition, and the optimized method on the temperature variation are evaluated. Finally, the proper optimized method for the recorded images under different heat sources is proposed.

\section{Experimental Program}

2.1. Specimens and Material. To analysis the surface temperature distribution above the defect, two groups of specimens with dimensions of $400 \times 170 \times 70 \mathrm{~mm}$ and $1000 \times 540 \times 170 \mathrm{~mm}$ were adopted in the test. In group A, two specimens with four defects were tested to evaluate the depth of the defect on the temperature distribution under pulse heating. In group B, a specimen with eight defects was used to study the effect of the size and depth of the defects on the temperature distribution under solar heating. The detailed dimension and distribution of defects are depicted in Figure 1. Concrete with a designed strength of $30 \mathrm{MPa}$ was adopted in the test and the mix proportion was cement: water: sand: coarse aggregate $=1: 0.62: 1.81: 4.20$. Before pouring the concrete, polyurethane foam with the same size as the defect was fixed in the design position by steel wire. As the thermal conductivity of the foam is close to that of air, the polyurethane foam can be used to simulate the defects in concrete [17].

2.2. Test Apparatus and Test Procedure. To analyze the application range of infrared thermography in nondestructive testing of concrete structures, quartz plate and sunlight were both used as heating sources to apply thermal energy to the specimens, as shown in Figure 2.

The pulse heating tests were carried out in the laboratory at a temperature of $25^{\circ} \mathrm{C}$. During the test, the quartz heating plate was first preheated for $2 \mathrm{~min}$ to keep the heating power stable and then placed above the specimen with a distance of $400 \mathrm{~mm}$. The heating power maintained $3000 \mathrm{~W}$ during the heating stage. After heating for $6 \mathrm{~min}$, the quartz plate was removed from the supports. In the meantime, an A300 infrared thermal imaging camera with a precision of $0.1^{\circ} \mathrm{C}$ and measuring range of $-20^{\circ} \mathrm{C} \sim 350^{\circ} \mathrm{C}$ was employed to record the surface temperature field. Considering the heat reflection generated in the heating stage is violent and the heat conduction is insufficient, it is not suitable to carry out defect identification in this period. At present, active heating research generally adopts the cooling stage, and the detection results are more accurate.

The solar heating tests were conducted under sunlight with a radiation intensity of about $800 \mathrm{~W} / \mathrm{m}^{2}$ and an ambient temperature of $33^{\circ} \mathrm{C}$. Generally, it is appropriate to apply solar heating in the morning because of the large temperature gradient of sunlight $[18,19]$. Before testing, the specimen was shaded to an ambient temperature of $25^{\circ} \mathrm{C}$ to eliminate the temperature difference and then exposed to sunlight for $30 \mathrm{~min}$. Meanwhile, the variation of surface temperature was recorded by the infrared thermal imaging camera. Since the sunlight is not controllable, it is inconvenient to conduct shading treatment in the signal acquisition process. No data on the cooling period was recorded, meaning that defects need to be identified during the heating phase.

2.3. Experimental Results. Figure 3 shows the surface temperature distribution of each specimen under the maximum temperature difference between the defect area and the intact area. It can be seen that the infrared thermal image detection method can be well used to detect the shallow defect in concrete.

In the pulse heating test, it is obvious that the brightness of deep defects A2-1 and A2-2 is higher than that of A1-2. This unexpected phenomenon is caused by the working principle of the thermal imager. The brightness of the infrared image is directly proportional to the temperature. The thermal imager assigns the brightest color to the highest temperature and the darkest color to the lowest temperature. However, the temperature range will change with time, and the brightness range remains unchanged, which means that the proportional coefficient of brightness and temperature is constantly changing. When there is an extremely hightemperature part (A1-1) in the image, the brightness range allocated to the relatively low-temperature area (A1-2) will be compressed, resulting in the brightness lower than A2-1 and A2-2, whose temperature is high and relatively close. The location of all the defects can be accurately determined; however, with the increase of the depth, the contours will be harder to distinguish.

In the solar heating test, the brightness corresponds well with the defect depth because the defects are located in the same image. When the defect depth is higher than $32 \mathrm{~mm}$, it is difficult to recognize the existence of the defect.

The subjective defect-recognition depends on the color difference between the defect area and the intact area. When the temperature difference is small, it is difficult for the naked eye to identify the defect, limiting the application of IRT. To further analyze the application range under pulse heating and solar heating manners, the average temperatures $(T)$ of defect area and intact area were extracted, and the temperature difference $(\Delta T)$ curves are shown in Figure 4.

Under pulse heating, it can be seen from Figure 3 that $\Delta T$ increases steadily in the early stage of cooling and then rises 


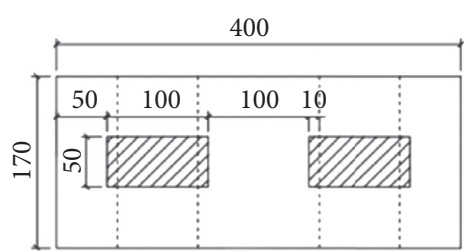

Vertical view of group A

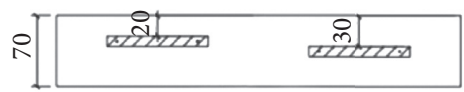

Front view of A1

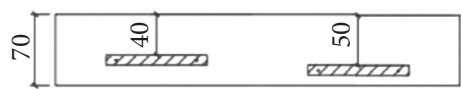

Front view of A2

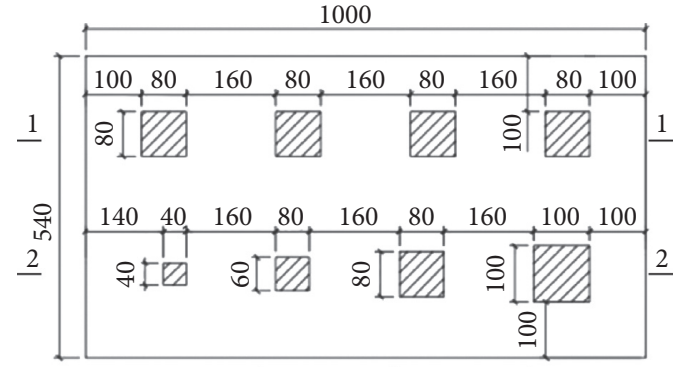

क[

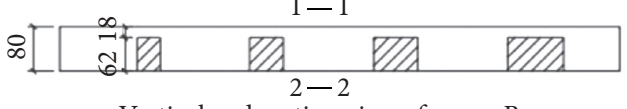

Vertical and section view of group B

Figure 1: Defect layout of specimens.

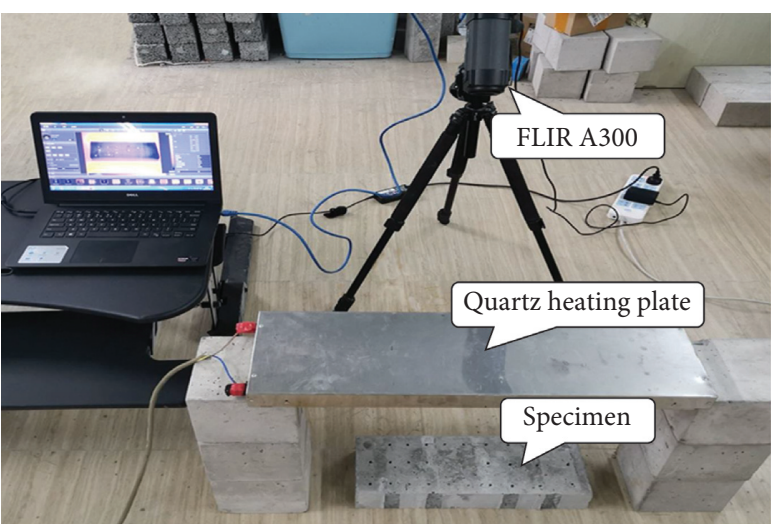

(a)

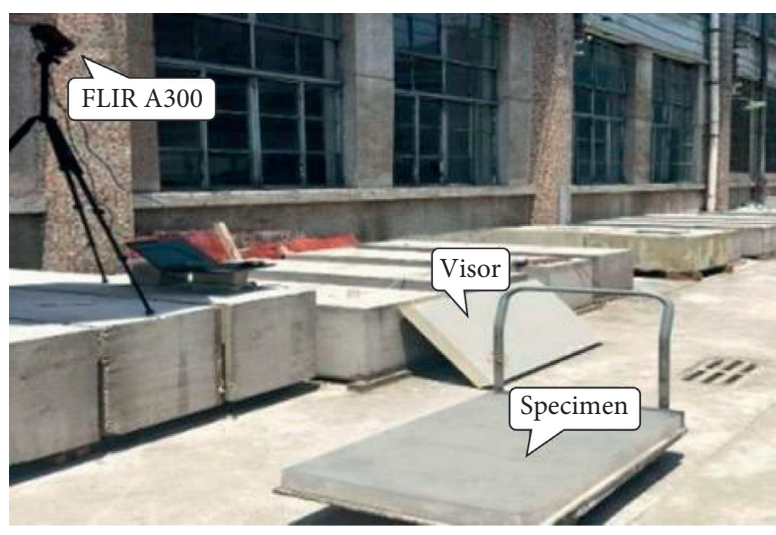

(b)

FIgure 2: Equipment layout. (a) Pulse heating. (b) Solar heating.

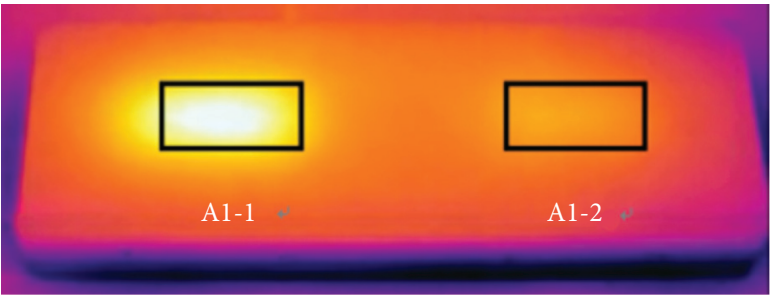

(a)

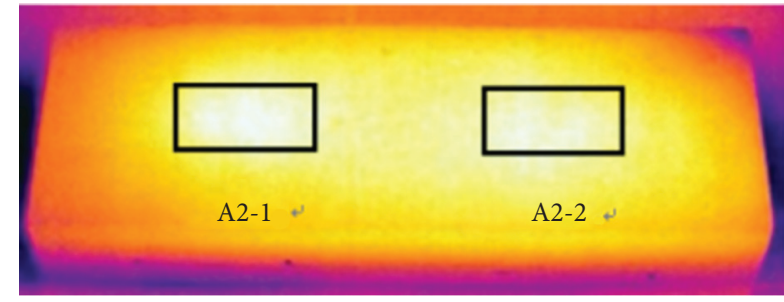

(b)

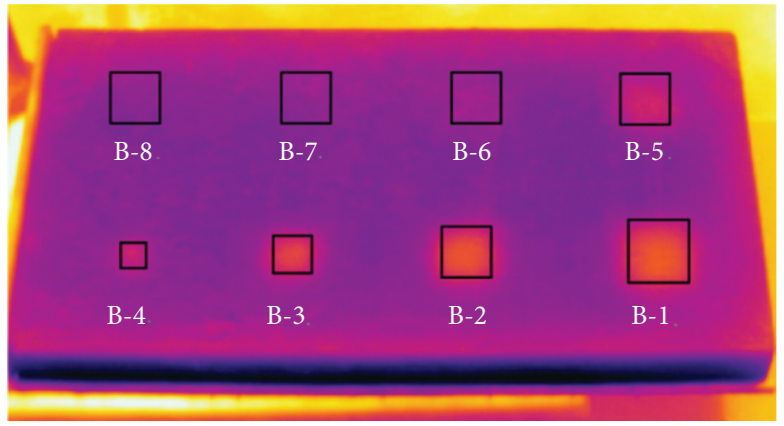

(c)

Figure 3: Temperature distribution. (a) A1-cool down for 12 minutes. (b) A2-cool down for 12 minutes. (c) B-heat up for 20 minutes. 

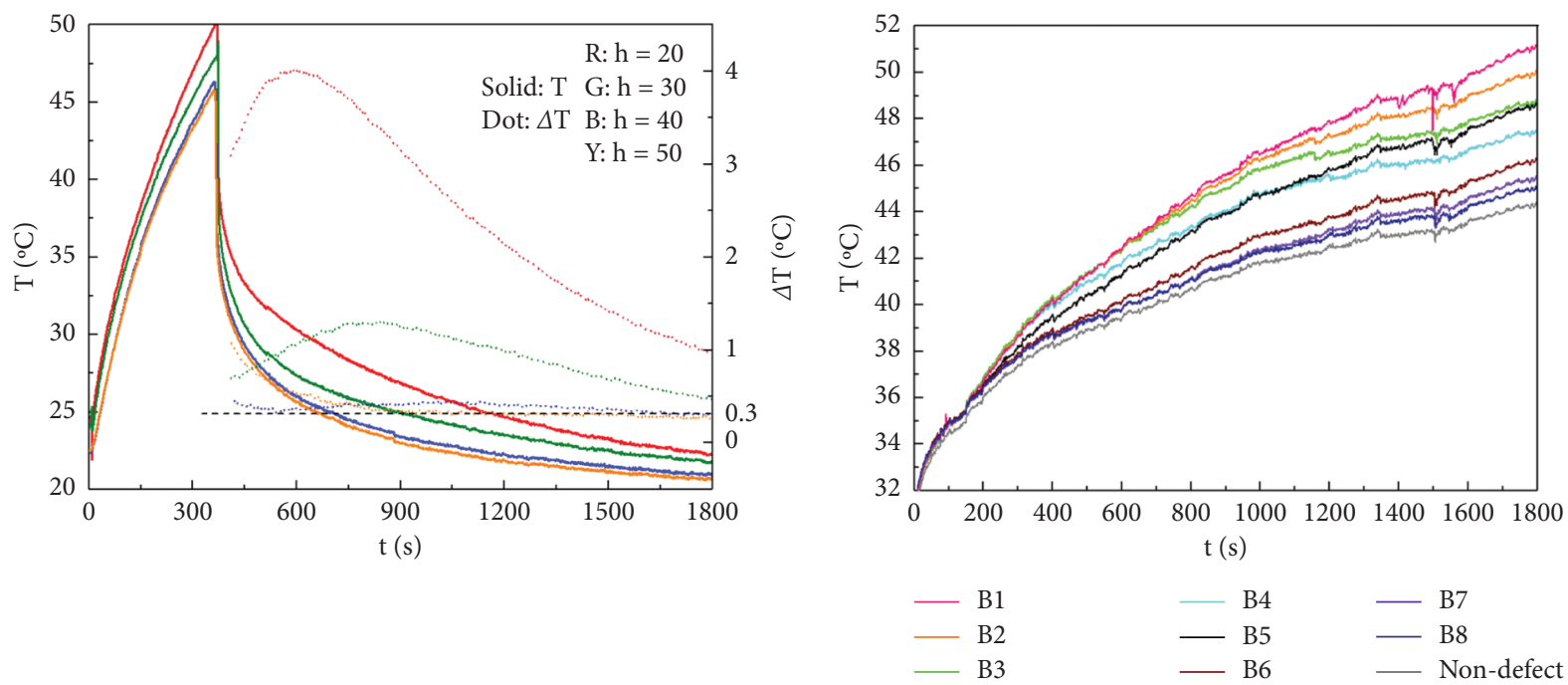

(a)

(b)

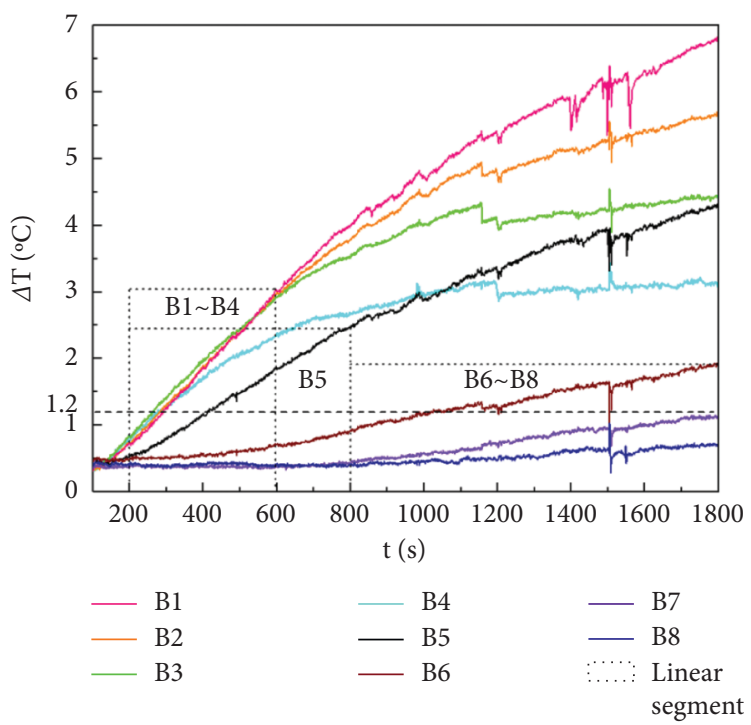

(c)

Figure 4: Temperature and temperature difference curve. (a) Pulse heating-T, $\Delta T$; (b) solar heating-T; (c) solar heating- $\Delta T$.

to the maximum value. However, it is difficult to distinguish the outline of deep defects when the temperature difference is less than $0.3^{\circ} \mathrm{C}$ (A2-1, A2-2). For solar heating, it can be found from Figure 4 that when the temperature difference is less than $1.2^{\circ} \mathrm{C}(\mathrm{B}-7, \mathrm{~B}-8)$, the defects cannot be accurately identified with naked eyes. To analyze the influence of dimension and depth of the defect on $\Delta T$, the ratio $(R)$ of side length $(L)$ to depth $(D)$ and the corresponding temperature difference is listed in Table 1 and Figure 5.

It can be seen from Figure 5 that it is hard to distinguish the defect when the ratio is less than 1.8. Therefore, it is necessary to optimize for this type of defect.

Meanwhile, to make infrared thermography detection more accurate in depth judgment, the temperature difference growth rate $(S)$ and the corresponding time of the linear segment of the temperature difference curve in Figure 4 are extracted in Table 2.
TABLE 1: Growth rate of temperature difference.

\begin{tabular}{lcccccccc}
\hline Def. & B1 & B2 & B3 & B4 & B5 & B6 & B7 & B8 \\
\hline$L(\mathrm{~mm})$ & 100 & 80 & 60 & 40 & 80 & 80 & 80 & 80 \\
$D(\mathrm{~mm})$ & 18 & 18 & 18 & 18 & 20 & 32 & 44 & 56 \\
$R$ & 5.6 & 4.4 & 3.3 & 2.2 & 4.0 & 2.5 & 1.8 & 1.4 \\
$\Delta T\left({ }^{\circ} \mathrm{C}\right)$ & 5.32 & 4.73 & 4.02 & 2.99 & 3.28 & 1.22 & 0.68 & 0.48 \\
\hline
\end{tabular}

It can be seen from Table 2 that when $D=18 \mathrm{~mm}$ (B1 B4), $L$ has little influence on $S$, which remains nearly 0.0058 . When $L=80 \mathrm{~mm}$ (B2, B5 B8), with the increase of $D, S$ decreases significantly. As a result, $S$ is mainly related to $D$, and $L$ exerts a minor influence on it. It can be seen from Figure 6 that a power function can represent the relationship between $S$ and $D$ and be used to judge the depth of the defects. The maximum detection depth can also be obtained. 


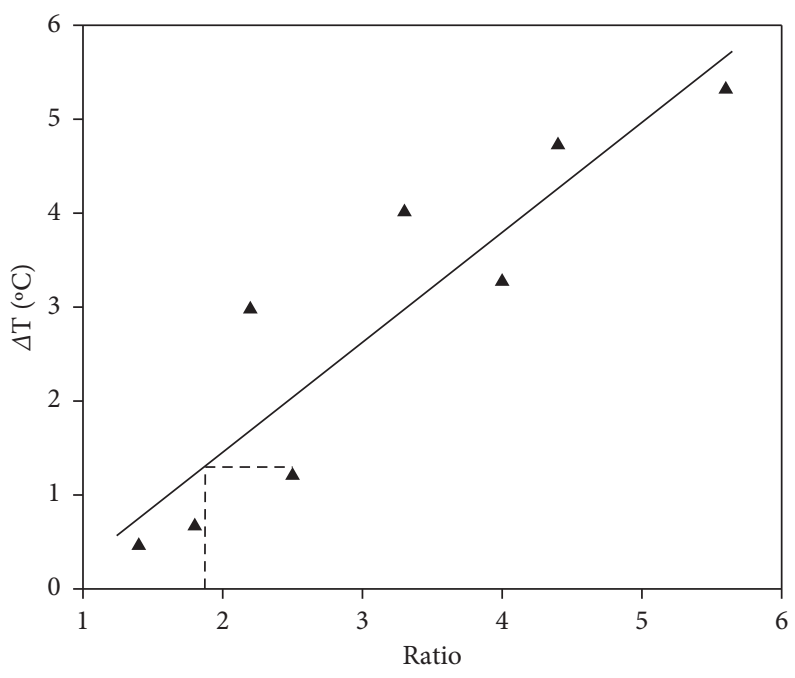

\ Test data

FIgURe 5: Ratio fitting.

TABLE 2: Growth rate of temperature difference.

\begin{tabular}{|c|c|c|c|c|c|c|c|c|}
\hline Def. & B1 & B2 & B3 & B4 & B5 & B6 & B7 & B8 \\
\hline$L[\mathrm{~mm}]$ & 100 & 80 & 60 & 40 & 80 & 80 & 80 & 80 \\
\hline$D(\mathrm{~mm})$ & 18 & 18 & 18 & 18 & 20 & 32 & 44 & 56 \\
\hline Time range(s) & \multicolumn{4}{|c|}{$200 \sim 600$} & \multicolumn{2}{|c|}{$200 \sim 800$} & \multicolumn{2}{|c|}{$>800$} \\
\hline$S$ & 0.0058 & 0.0058 & 0.0059 & 0.0050 & 0.0034 & 0.0014 & 0.0009 & 0.0005 \\
\hline
\end{tabular}

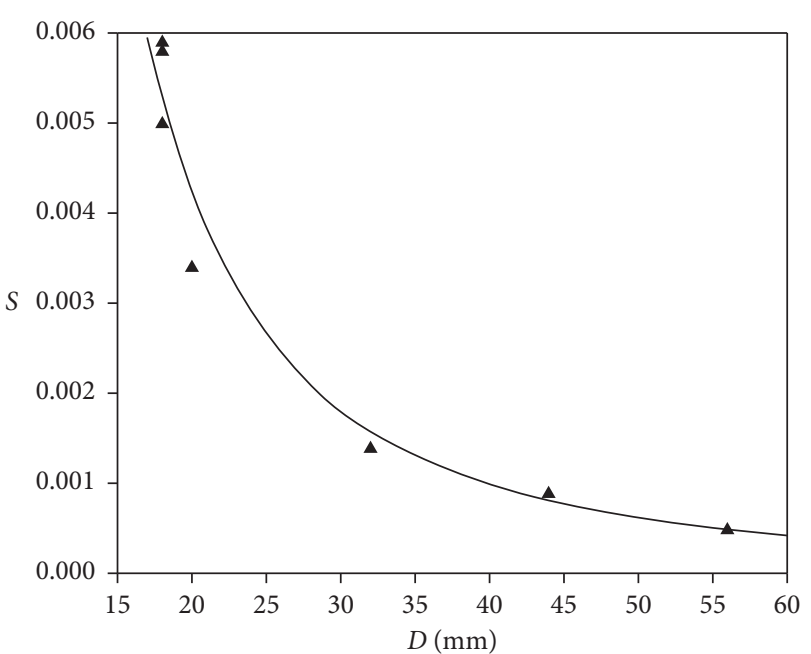

\ Test point

Figure 6: Slope fitting.

\section{Optimized Method of Image}

3.1. Interference Cancellation. Generally, the IRT detection mainly uses the temperature field at a single moment to identify defects [20], but the recorded information is easily disturbed by the external noise. During the tests, the thermal imaging camera can record the whole variety of the surface temperature. To make full use of the recorded data and reduce the influence of external noise on images, the video was decomposed into single-frame images with equal interval time. After that, the gray value of each pixel point is fitted with $n$ times polynomial equation in chronological order $[10,16]$, and the fitting value of surface temperature $T(t)$ can be expressed as follows:

$$
T(t)=\sum_{(i=0)}^{n} a_{i} t^{i}=a_{0}+a_{1} t+a_{2} t^{2}+\cdots+a_{n} t^{n} .
$$

The experimental material is not an ideal semi-infinite body. In the process of solar heating, the deviation of illumination angle and ambient temperature will affect the boundary temperature of the sample. However, in the process of active heating, the pulse intensity is much greater than the environmental impact which can be ignored. As shown in Figure 7, to study the temperature variation at the material boundary and propose an effective correction method, the image is corrected by perspective transformation to ensure the authenticity of the defect information [21-23], and two measuring lines are arranged in the detection image to extract the gray value (proportional to the temperature) along the line.

It can be seen from Figure 7 that the temperature around the boundary region is higher than the central part of the specimen. Moreover, the temperature above the defect is larger than the intact area-the deeper the defect, the lower the temperature. Therefore, the temperature of the specimen is influenced by solar radiation, defects, and boundaries. To obtain the actual temperature above the defect, the effect of the boundary should be eliminated. For an intact area, the 


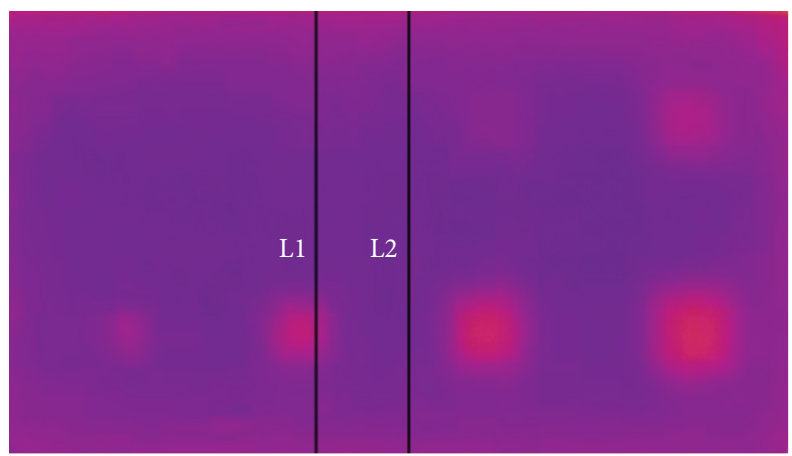

(a)

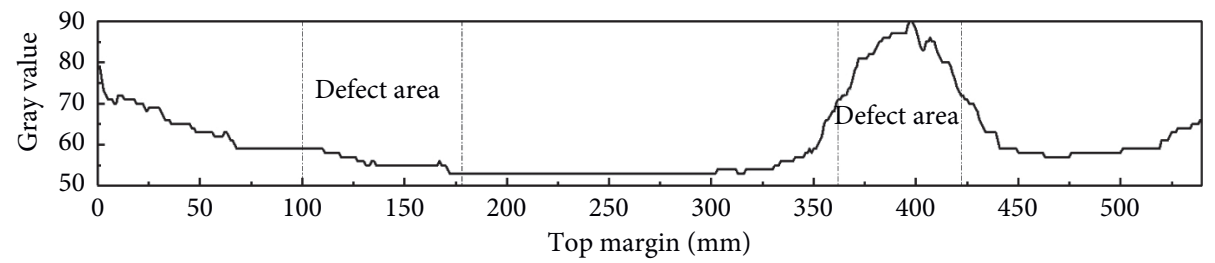

(b)

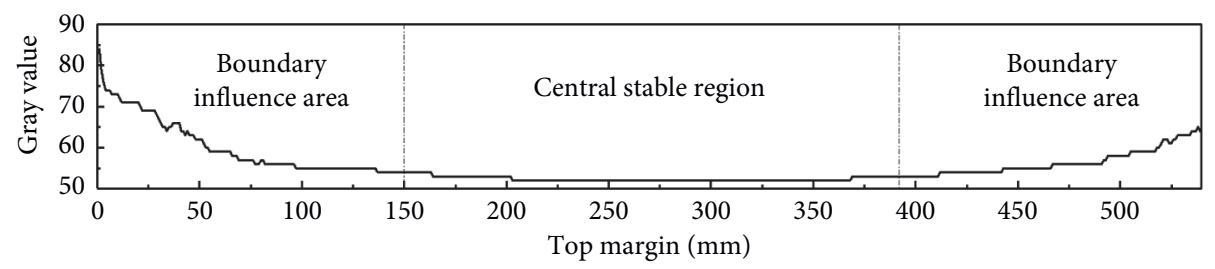

(c)

Figure 7: Line layout and gray level. (a) Line layout. (b) L1-gray level. (c) L2-gray level.

surface temperature is related to the solar radiation and boundary. During the test, the radiation was uniformly applied to the concrete. The influence of solar radiation on the temperature can be regarded as a fixed value at a particular moment. The boundary effect mainly controls the variation of temperature around the boundary region. Therefore, the average temperature on the left side of Figure $7(\mathrm{c})$ can be described in Figure 8.

As illustrated in Figure 8, the horizontal asymptote of the fitting curve can be regarded as the dividing line between the effect of solar radiation and boundary, and the influence of boundary effect can be eliminated by subtracting the part enclosed by the horizontal asymptote and the fitting curve. Therefore, the infrared 3D image of the specimen B after subtracting can be obtained in Figure 9.

The image preprocessing effectively eliminates external interference and makes the temperature in the nondefect area more stable, but the deep defects are still not highlighted, so it is necessary to further optimize the preprocessed image.

3.2. Image Enhancement. The infrared detection image is different from the ordinary image by reason of the simple distribution of color blocks, no sudden change in brightness, and few details available. When processing this kind of image, the effect of many algorithms based on visual and multiscale information is close to that of histogram equalization. However, the histogram algorithm has the advantages of convenient adjustment and fast operation speed, so the global histogram equalization (GHE) and the contrast limit adaptive histogram equalization (CLAHE) method were adopted in this passage [24-29].

GHE is a method of applying histogram equalization directly to the whole image by broadening the gray value that occupies most of the image and merges the gray value with a small number to enhance image contrast. The transform function can be obtained through the histogram information of the image. CLAHE first subdivides the image into a square subarray. Then, the exceeding default gray values are distributed to each pixel to make the high-temperature area's gray value tend to be consistent. This approach abandons the idea of uniform transition and transforms the region into a ladder form so that the contours of the high-temperature parts can be highlighted. The optimization results of pulse heating and solar heating under different enhancement image algorithms are shown in Figures 10 and 11.

It can be seen from Figure 10 that the enhanced image algorithm can improve defect-recognition resolution. For pulse heating, the heat around the defect was continuously transmitted to the surrounding parts during the cooling stage. For shallow defect, as shown in Figures 10(b) and 10(e), the GHE method results in a large red speckle formed above the defect, and the shape of the defect is hard to be 


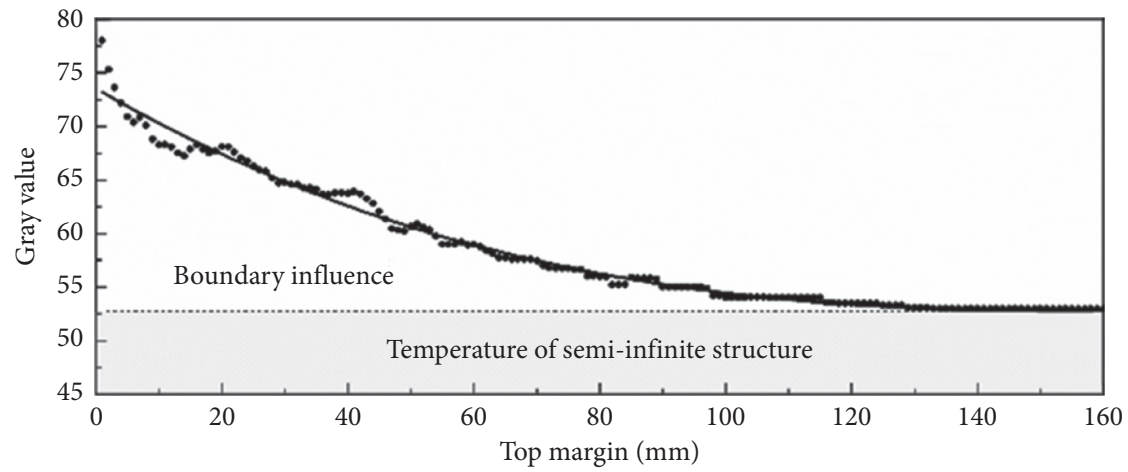

- Average gray value

FIgURE 8: Edge temperature fitting.

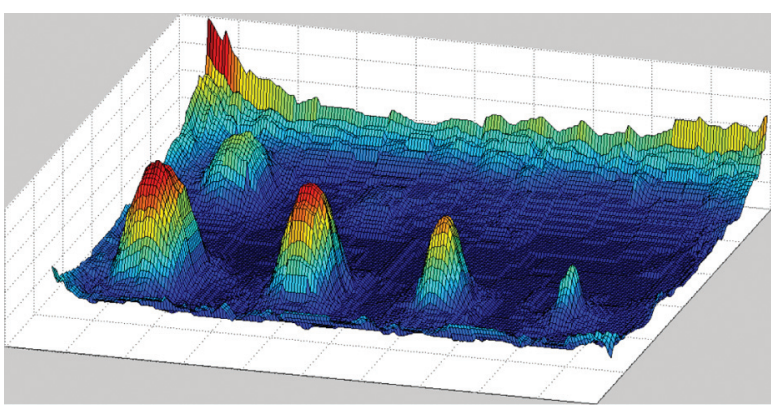

(a)

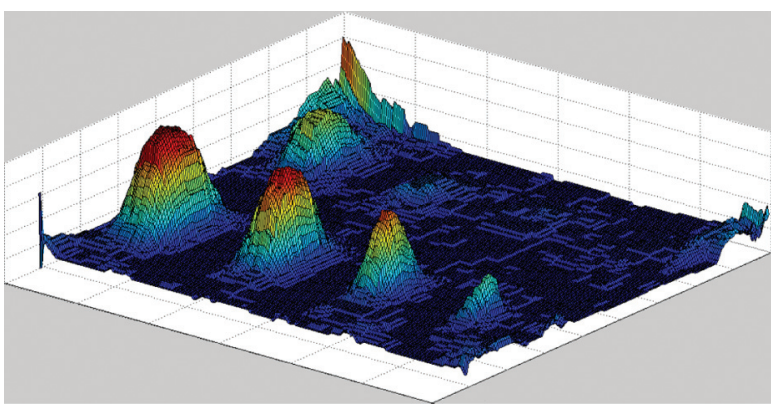

(b)

FIgURE 9: Preprocessing effect of specimen B. (a) Before preprocessing. (b) After preprocessing

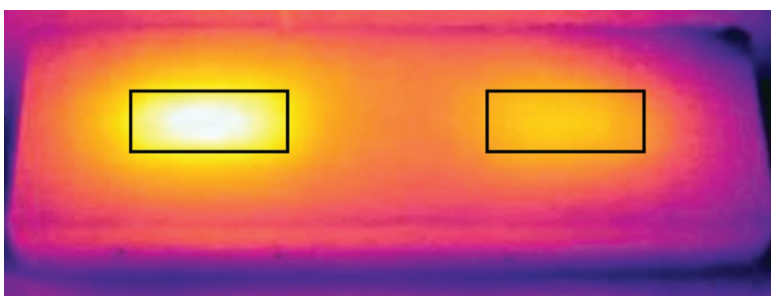

(a)

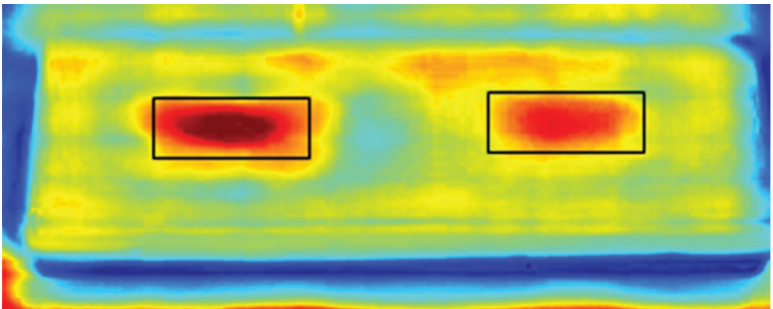

(c)

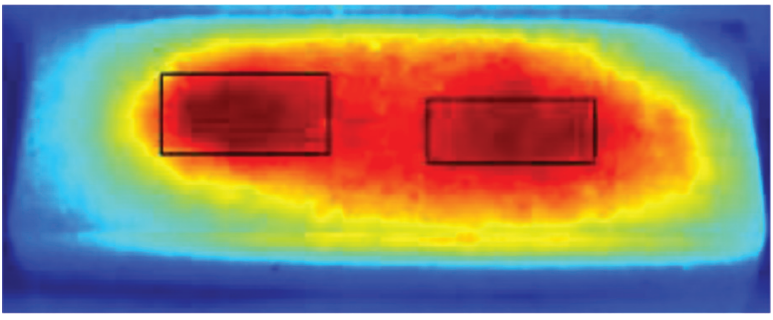

(e)

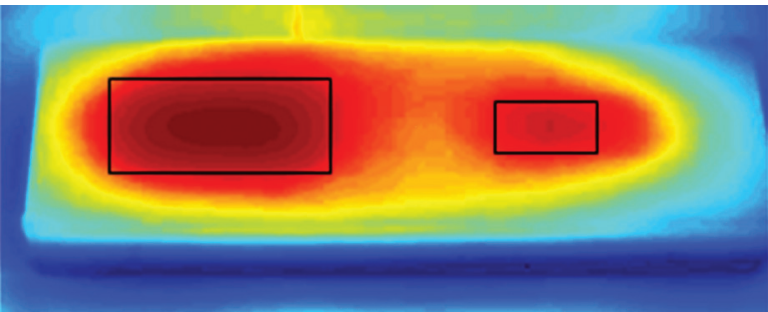

(b)

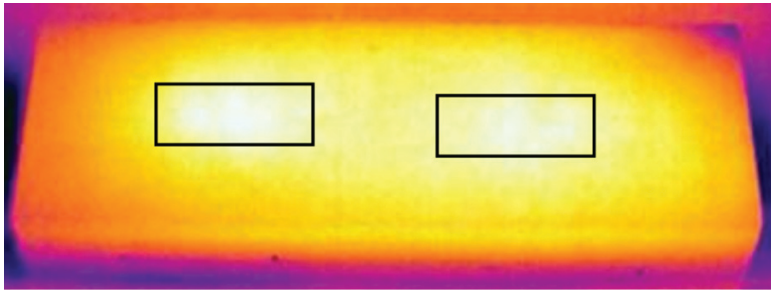

(d)

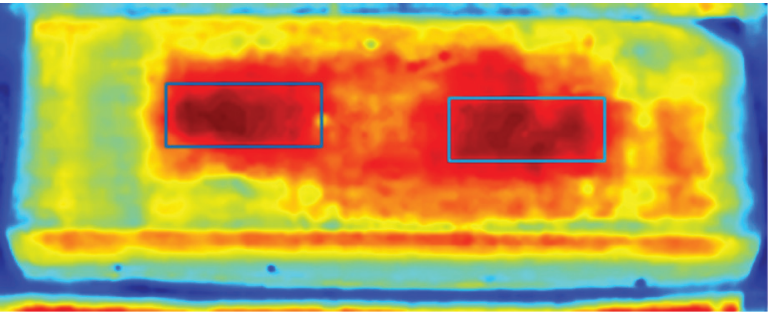

(f)

Figure 10: Comparison image enhancement of A1 and A2. (a) A1-before enhancement. (b) A1-GHE enhancement. (c) A1-CLAHE enhancement. (d) A2-before enhancement. (e) A2-GHE enhancement. (f) A2-CLAHE enhancement. 


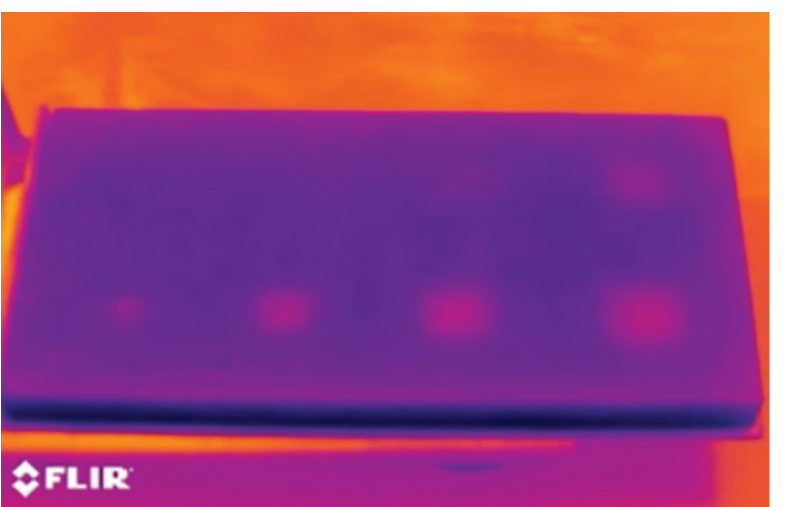

(a)

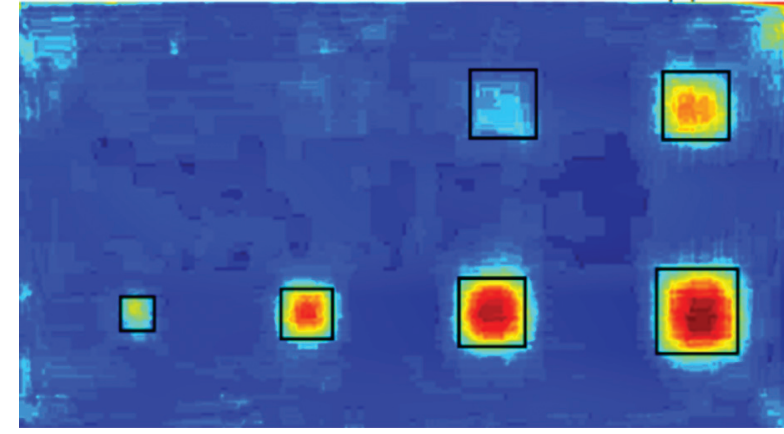

(b)

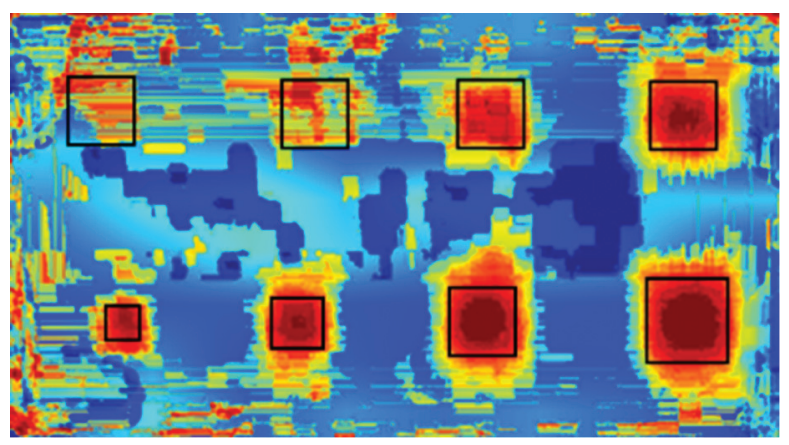

(c)

FIGURE 11: Comparison image enhancement of B. (a) B-before image enhancement. (b) B-CLAHE enhancement. (c) B-GHE enhancement.

discriminated. However, it can be seen from Figure 10(c) that the location and the shape of the defect are easy to be distinguished after the image was enhanced by the CLAHE method. At this point, the use of CLAHE was more effective in shaping defect contours.

As shown in Figure 11, it is difficult to identify deeper defects after the optimization by the CLAHE algorithm. However, the GHE algorithm can equalize the whole image and extend the range of compressed pixels, which could effectively improve the contrast of the deep defects.

Root mean square contrast $\sigma_{I}$ and area ratio $z_{s}$ are used to measure the identification effect and accuracy of defects to objectively compare the advantages of different image enhancement algorithms and image quality after processing. The calculation method is as follows [30]:

$$
\begin{aligned}
& \sigma_{I}=\sqrt{\frac{1}{(m \times n)} \cdot \sum_{I_{m \times n}}\left(I(x, y)-a^{2}\right)}, \\
& z_{s}=\frac{s_{0}}{s_{d}}
\end{aligned}
$$

where $I(x, y)$ is gray value at point $(x, y) ; s_{0}$ is area of the embedded defect; and $s_{d}$ is area of the actual detection.

According to equations (2) and (3), the optimization parameters of each defect area before and after using different enhanced image algorithms in Figures 10 and 11 are shown in Table 3.
TABle 3: Optimization parameters.

\begin{tabular}{lccccccc}
\hline Def. & $\Delta T\left({ }^{\circ} \mathrm{C}\right)$ & \multicolumn{3}{c}{$\sigma_{I}$} & & \multicolumn{3}{c}{$z_{s}$} \\
& & Initial & CLAHE & GHE & Initial & CLAHE & GHE \\
\hline A1-1 & 3.5 & 32.6 & 56.5 & 60.4 & 0.86 & 1.04 & - \\
A1-2 & 1.2 & 14.8 & 39.0 & 54.5 & 1.18 & 0.93 & 0.81 \\
A2-1 & 0.4 & 22.3 & 65.0 & 60.3 & - & 0.73 & 0.80 \\
A2-2 & 0.4 & 16.6 & 53.7 & 51.2 & - & 0.77 & 0.85 \\
B-1 & 5.7 & 12.1 & 56.5 & 61.6 & 1.08 & 1.24 & 1.30 \\
B-2 & 4.3 & 10.2 & 54.5 & 65.2 & 1.14 & 1.36 & 1.27 \\
B-3 & 4.0 & 7.8 & 48.3 & 59.8 & 1.35 & 1.27 & 1.23 \\
B-4 & 3.0 & 4.4 & 45.5 & 55.9 & 0.71 & 1.26 & 1.29 \\
B-5 & 3.3 & 5.6 & 31.1 & 61.0 & 0.89 & 1.16 & 1.28 \\
B-6 & 1.2 & 1.9 & 29.5 & 58.5 & - & 0.94 & 1.13 \\
B-7 & 0.7 & - & 15.8 & 55.2 & - & 0.88 & 1.10 \\
B-8 & 0.5 & - & - & 51.3 & - & - & 1.03 \\
\hline
\end{tabular}

It can be seen from Table 3 and Figures 10 and 11 that both CLAHE and GHE algorithms can effectively improve the recognition effect of internal defects in infrared thermal images. CLAHE algorithm makes temperature ladder-type through local processing, which better shapes the defect profile without causing defect distortion. However, it is not suitable for areas with low initial contrast $\left(\sigma_{I}<5.6\right)$ or lowtemperature gradient, so that the optimization effect of deep defects $(h>32 \mathrm{~mm})$ under solar heating is not good enough.

GHE algorithm, by expanding the pixel interval of the full image, increases the gray value of the small proportion of the defected part. The increase of defect depth has little influence on the optimization effect. After application, the 
defect area is enlarged by 1.0 1.3 times while the line error is kept between 0 and 15\%. Under the experimental conditions in this paper, the effective detection depth under solar heating can be increased from $30 \mathrm{~mm}$ to $55 \mathrm{~mm}$, with an increase of more than $80 \%$.

3.3. Discussion. In this paper, we combine some simple image processing algorithms with infrared defect detection of concrete and obtain some positive results.

In the past, the optimization of infrared detection of concrete mainly focuses on the improvement of heating mode and instruments. The continuous optimization of hardware facilities is pleasant, but it may face some limitations in the practical application process. Therefore, this paper adopts a common heat source for assistance and combines the algorithm to optimize the detection results. For simple detection images, some commonly used algorithms, such as histogram equalization, can play a good processing effect and are not inferior to the complex algorithm. At the same time, the algorithm principle determines its applicable scope. We tentatively put forward that GHE can improve the contrast and is more suitable for highlighting deep defects, while CLAHE can shape the defect contour better. The results of the experiment can also prove this point.

Although there are important discoveries revealed by these studies, there are also limitations. First, there are few types of defects arranged, and the influence of environmental humidity, air convection, and other potential influencing factors is not considered in the test process, so the simulation is not comprehensive enough. At the same time, the quantification of defect depth requires a large number of tests to determine the query parameters. Therefore, we hope to share more research data and further subdivide the experimental conditions according to different working conditions in order to draw more general conclusions. Second, the intelligent degree is not satisfactory, and subjective judgment is required in many aspects. Neural network learning may be a good solution.

\section{Conclusion}

Experimental research has been carried out to detect the internal defects in concrete by infrared thermography, and the thermograph was optimized by image preprocessing and enhancement algorithm. The main conclusions from the results are summarized as follows:

(1) Under sunlight heating, the defect can be easily distinguished when the ratio of side length to depth is larger than 1.8.

(2) The depth of defects can be preliminarily determined according to the combination of heating rate and set parameters.

(3) The impact of view angle, temperature fluctuation, and boundary conditions on the thermal image can be reduced by image preprocessing, such as signal reconstruction and transformation and temperature division.

(4) GHE can stretch the temperature scale and is more suitable for deep defect-recognition under solar heating. The ladder processing of CLAHE is more suitable for pulse heating images with blurred defect contours.

\section{Data Availability}

The data used to support the findings of this study are available from the corresponding author upon request.

\section{Conflicts of Interest}

The authors declare that there are no conflicts of interest regarding the publication of this paper.

\section{Acknowledgments}

This work was supported by the National Natural Science Foundation of China (51479013 and 51809025) and Chongqing Youth Science and Technology Talent Training Program (CSTC2014KJRC-QNRC30001).

\section{References}

[1] G. J. Weil, "Nondestructive testing of airport concrete structures: runways, taxiways, roads, bridges, and building walls and roofs," Nondestructive Evaluation of Aging Aircraft, Airports, and Aerospace Hardware II, The International Society for Optical Engineering, vol. 3397, 1998.

[2] C. Ibarra-Castanedo, J. R. Tarpani, and X. P. V. Maldague, "Nondestructive testing with thermography," European Journal of Physics, vol. 34, no. 6, pp. 91-109, 2013.

[3] C. C. Cheng, T. M. Cheng, and C. H. Chiang, "Defect detection of concrete structures using both infrared thermography and elastic waves," Automation in Construction, vol. 18, no. 1, pp. 87-92, 2009.

[4] N. P. Avdelidis, C. Ibarra-Castanedo, X. Maldague, Z. P. Marioli-Riga, and D. P. Almond, "A thermographic comparison study for the assessment of composite patches," Infrared Physics \& Technology, vol. 45, no. 4, pp. 291-299, 2004.

[5] B. Z. Wang, L. H. Dong, H. D. Wang et al., "Research and application of laser infrared thermography in material defect detection," Materials Reports, vol. 34, no. 3, pp. 127-132, 2020.

[6] C. Maierhofer, A. Brink, M. Röllig, and H. Wiggenhauser, "Detection of shallow voids in concrete structures with impulse thermography and radar," NDT \& E International, vol. 36, no. 4, pp. 257-263, 2003.

[7] P. Cotič, D. Kolaric, V. B. Bosiljkov, V. Bosiljkov, and Z. Jagličića, "Determination of the applicability and limits of void and delamination detection in concrete structures using infrared thermography," NDT \& E International, vol. 74, no. 9, pp. 87-93, 2015.

[8] Y. P. Tian, K. Y. Zhou, H. Liang et al., "Research on quantitative evaluation of infrared thermography," Chinese Journal of Scientific Instrument, vol. 29, no. 11, pp. 2413-2418, 2008.

[9] X. P. Maldague, "Theory and practice of infrared technology for nondestructive testing," Chapter, vol. 4, no. 3, p. 307, 2001. 
[10] K. Chatterjee, S. Tuli, S. G. Pickering, and D. P. Almond, "A comparison of the pulsed, lock-in and frequency modulated thermography nondestructive evaluation techniques," NDT \& E International, vol. 44, no. 7, pp. 655-667, 2011.

[11] R. Krankenhagen and C. Maierhofer, "Pulse phase thermography for characterising large historical building façades after solar heating and shadow cast-a case study," Quantitative InfraRed Thermography Journal, vol. 11, no. 4, pp. 1028, 2014.

[12] M. R. Clark, D. M. Mccann, and M. C. Forde, "Application of infrared thermography to the non-destructive testing of concrete and masonry bridges," NDT \& E International, vol. 36, no. 4, pp. 265-275, 2003.

[13] Z. Wang and A. C. Bovik, Modern Image Quality Assessmentpp. 1-10, National Defense Industry Press, Beijing, China, 1st edition, 2015.

[14] K. Singh, D. K. Vishwakarma, G. S. Walia, and R. Kapoor, "Contrast enhancement via texture region based histogram equalization," Journal of Modern Optics, vol. 63, no. 15, pp. 1-7, 2016.

[15] Z. G. Xu, X. M. Zhao, H. S. Song, T. Lei, and N. Wei, “Asphalt pavement crack recognition algorithm based on histogram estimation and shape analysis," Chinese Journal of Scientific Instrument, vol. 31, no. 10, pp. 2260-2266, 2010.

[16] S. B. Tian, Y. Yang, Z. Liu, C. Wang, and R. H. Pan, "Enhancement of infrared images based on efficient histogram processing," Wireless Personal Communications, vol. 99, no. 2, pp. 619-636, 2018.

[17] P. Cotič, Z. Jagličić, E. Niederleithinger, M. Stoppel, and V. Bosiljkov, "Image fusion for improved detection of nearsurface defects in NDT-CE using unsupervised clustering methods," Journal of Nondestructive Evaluation, vol. 33, no. 3, pp. 384-397, 2014.

[18] J. H. A. Rocha and Y. V. Póvoas, "Detección de delaminaciones en puentes de concreto armado usando Termografía Infrarroja," Revista ingeniería de construcción, vol. 34, no. 1, pp. 55-64, 2019.

[19] S. Sfarra, E. Marcucci, D. Ambrosini, and D. Paoletti, "Infrared exploration of the architectural heritage: from passive infrared thermography to hybrid infrared thermography (HIRT) approach," Materiales de Construcción, vol. 66, no. 323, p. e094, 2016.

[20] C. Maierhofer, H. Wiggenhauser, A. Brink, and M. Röllig, "Quantitative numerical analysis of transient IR-experiments on buildings," Infrared Physics and Technology, vol. 46, no. 1, pp. 73-80, 2004.

[21] H. Zhen, J. Li, H. X. Chen, and Z. Li, "Research on fast algorithm for parallel correction of distorted infrared image," Chinese Journal of Scientific Instrument, vol. 32, no. 11, pp. 2530-2535, 2011.

[22] D. J. Titman, "Applications of thermography in non-destructive testing of structures," NDT \& E International, vol. 34, no. 2, pp. 149-154, 2001.

[23] M. Weiser, M. Roellig, R. Arndt, and B. Erdmann, "Development and test of a numerical model for pulse thermography in civil engineering," Heat \& Mass Transfer, vol. 46, no. 11-12, pp. 1419-1428, 2010.

[24] Z. Q. Feng, B. Gao, Y. Yang, and G. Y. Tian, "Debonding defect detection of CFRP based on thermal signal reconstructed region growing algorithm," Nondestructive Testing, vol. 9, pp. 29-34, 2017.

[25] Y. T. Liu, Z. Chen, Z. F. Fu, and F. X. Zheng, "Infrared image enhancement algorithm based on CLAHE," Laser \& Infrared, vol. 46, no. 10, pp. 1290-1294, 2016.
[26] M. Abdullah-Al-Wadud, M. Kabir, M. Akber Dewan, and O. Chae, "A dynamic histogram equalization for image contrast enhancement," IEEE Transactions on Consumer Electronics, vol. 53, no. 2, pp. 593-600, 2007.

[27] R. C. Gonzalez, R. E. Woods, and S. L. Eddins, Digital Image Processing Using MATLAB, pp. 197-199, Prentice Hall, Upper Saddle River, CF, USA, 2010.

[28] K. Liang, Y. Ma, Y. Xie, B. Zhou, and R. Wang, "A new adaptive contrast enhancement algorithm for infrared images based on double plateaus histogram equalization," Infrared Physics \& Technology, vol. 55, no. 4, pp. 309-315, 2012.

[29] C. Y. Wong, G. Jiang, M. A. Rahman et al., "Histogram equalization and optimal profile compression based approach for colour image enhancement," Journal of Visual Communication and Image Representation, vol. 38, no. 7, pp. 802-813, 2016.

[30] A. A. Bhuiyan and A. R. Khan, "Image quality assessment employing RMS contrast and histogram similarity," International Arab Journal of Information Technology, vol. 15, no. 6, pp. 983-989, 2018. 